\title{
Noninfectious Pulmonary Complications after Stem Cell Transplantation and Induction of an Innate Immune Response
}

\author{
Makoto Onizuka ${ }^{1^{*}}$, Koich Miyamura ${ }^{2}$, Mitsuki Miyamoto ${ }^{1}$ and Kiyoshi Ando ${ }^{1}$ \\ ${ }^{1}$ Department of Hematology and Oncology, Tokai University School of Medicine, Isehara, Kanagawa, Japan \\ ${ }^{2}$ Bone Marrow Transplantation Center, Japanese Red Cross Nagoya First Hospital, Aichi, Japan
}

"Corresponding author: Makoto Onizuka, Department of Hematology and Oncology, Tokai University School of Medicine, 143 Shimokasuya, Isehara, Kanagawa, 259-1143, Japan, Tel: +81-463-93-1121; Fax: +81-463-92-4511; E-mail: moni5@mac.com

Received date: Mar 20, 2015, Accepted date: May 11, 2015, Publication date: May 18, 2015

Copyright: $\odot 2015$ Onizuka M, et al. This is an open-access article distributed under the terms of the Creative Commons Attribution License, which permits unrestricted use, distribution, and reproduction in any medium, provided the original author and source are credited.

\begin{abstract}
Introduction: Non-infectious pulmonary dysfunction (NIPC) represents a common and often fatal complication of hematopoietic stem cell transplantation (HSCT). Recently, bactericidal/permeability-increasing (BPI) haplotypes were associated with an increased risk of developing airflow decline after HSCT.
\end{abstract}

Objective: In order to clarify whether BPI is involved in the pathogenesis of HSCT-related pulmonary complications, we performed a genetic association study.

Methods: In this study, we therefore investigated the relationship between BPI and pulmonary dysfunction within an ethnic group by analyzing the incidence of NIPC based on genotype and the allelic frequency of BPI polymorphisms in 121 Japanese patients who underwent HSCT from HLA-identical sibling donors. We examined BPI-associated single nucleotide polymorphisms (SNPs) (rs5741798, rs1934917, rs5743530, rs2275954), and identified NIPC-associated polymorphisms in 20 patients $(16.5 \%)$

Results: The allelic frequencies of rs1934917 and rs5743530 are significantly different between patients with and without NIPC $(P=0.024$ and $P=0.015$, respectively). For donors, the rs $5743530 \mathrm{C}$ allele was more frequent in the NIPC group than in the group without NIPC $(P=0.038)$. No significant relationships were noted between each of the other gene polymorphisms and the development of NIPC.

Conclusion: In this Japanese cohort study, two candidate SNPs reached statistical significance in terms of NIPC incidence and our findings suggest that BPI haplotypes contribute to the development of NIPC within an ethnic group.

Keywords: Non-infectious pulmonary complication; Stem cell transplantation; Genetic association study; BPI

\section{Introduction}

Hematopoietic stem cell transplantation (HSCT) has become the standard treatment for many hematological disorders. Nevertheless, a number of complications associated with either acute or chronic graft versus host disease (aGVHD, cGVHD) have limited the utility of HSCT. In particular, infectious and noninfectious pulmonary complications occur in $25-50 \%$ of allogeneic HSCT recipients, and can account for approximately $50 \%$ of transplant-related deaths $[1,2]$. Noninfectious pulmonary complications (NIPC) have a wide etiological spectrum. Early-onset NIPC include diffuse alveolar hemorrhage (DAH) and the idiopathic pneumonia syndrome (IPS), while late-onset NIPC mainly comprise bronchiolitis obliterans syndrome (BOS) and bronchiolitis obliterans with organizing pneumonia (BOOP) [2-6]. Since little is known about the pathogenesis of NIPC, neither its incidence nor prognosis have improved since the first description of this condition over 20 years ago.

Predicting the likely outcome of HSCT has been aided by the analysis of both non-histocompatibility leukocyte antigen (non-HLA) functional genomics and conventional risk factors [7-10]. Indeed, recent studies focusing on patients' genetic background with respect to HSCT-related complications have shed light on the pathogenesis of GVHD [8]. Although pulmonary dysfunction after HSCT is a serious complication, only two studies have described the relationship between genomic polymorphisms and pulmonary complications after HSCT [11-13]. To this end, Chien et al. [5] identified an association between bactericidal/permeability-increasing protein (BPI) and rapid airflow decline, indicating a role for innate immunity in BOS after HSCT. In addition, lipopolysaccharide (LPS) activates alveolar macrophages via LPS-binding protein to induce the production of specific cytokines and subsequent rapid but transient neutrophil infiltration into the lung (interstitium, alveoli, and airways) [14]. LPS thus can cause chronic airway inflammation in various airway diseases including asthma, chronic bronchitis, and emphysema [15], and LPS together with pro-inflammatory cytokine, TNF- $\alpha$, have important roles in the development of IPS [16,17]. These insights led us to hypothesize that BPI is also involved in the pathogenesis of HSCTrelated pulmonary complications. Therefore, we have analyzed the association of BPI gene polymorphisms and NIPC, including BOS, in the Japanese population. 
Citation: Onizuka M, Miyamura K, Miyamoto M, Ando K (2015) Noninfectious Pulmonary Complications after Stem Cell Transplantation and Induction of an Innate Immune Response. J Blood Disord Transfus 6: 277. doi:10.4172/2155-9864.1000277

Page 2 of 6

\section{Materials and Methods}

\section{Study patients}

A total of 121 consecutive patients received allogeneic bone marrow (BM) or peripheral blood stem cell transplantation from their HLAidentical sibling donors at the Japanese Red Cross Nagoya First Hospital during the years from 1987 to 2003. HLA matching among donor-recipient pairs was confirmed by either family study or genotyping in all patients. Patients who received T-cell-replete transplantation and cyclosporin $\mathrm{A}(\mathrm{CyA})$ in combination with shortterm methotrexate (MTX) as a GVHD prophylaxis were selected to participate in the study. CyA was administered daily from day 1 at 3.0 $\mathrm{mg} / \mathrm{kg}$, initially via intravenous (IV) infusion, and then via oral administration at twice the IV dose when the patient's oral intake resumed. MTX was administered at $10 \mathrm{mg} / \mathrm{m}^{2}$ on day 1 and at 7 $\mathrm{mg} / \mathrm{m}^{2}$ on days 3 and 6 . Informed consent was obtained from all patients and donors, and the study was approved by the ethics committees at the Tokai University Hospital and Japanese Red Cross Nagoya First Hospital. Patient characteristics are shown in Table 1.

\begin{tabular}{|c|c|c|}
\hline & Patients with NIPC & Patients without NIPC \\
\hline & $(n=20)$ & $(n=101)$ \\
\hline Age, median (range), y & $35(16-54)$ & $35(15-55)$ \\
\hline \multicolumn{3}{|l|}{ Sex, $n$} \\
\hline Male & 13 & 59 \\
\hline Female & 7 & 42 \\
\hline \multicolumn{3}{|l|}{ Diagnosis,n } \\
\hline CML & 6 & 32 \\
\hline AML & 9 & 26 \\
\hline ALL & 2 & 21 \\
\hline MDS & 1 & 10 \\
\hline AA & 2 & 12 \\
\hline \multicolumn{3}{|l|}{ Conditioning, $n$} \\
\hline $\mathrm{CA}+\mathrm{CY}$ & 3 & 35 \\
\hline $\mathrm{BU}+\mathrm{CY}$ & 10 & 33 \\
\hline $\mathrm{BU}+\mathrm{ML}$ & 3 & 8 \\
\hline ML & 0 & 10 \\
\hline $\mathrm{CY}$ & 4 & 15 \\
\hline \multicolumn{3}{|l|}{ TBI dose, $\mathrm{n}$} \\
\hline $12 \mathrm{~Gy} \geq$ & 6 & 37 \\
\hline $10 \mathrm{~Gy} \geq$ & 7 & 45 \\
\hline $5 \mathrm{~Gy} \geq$ & 3 & 13 \\
\hline non TBI/TLI & 4 & 6 \\
\hline \multicolumn{3}{|l|}{ Acute GVHD, $\mathbf{n}$} \\
\hline $0 \sim 1$ & 15 & 87 \\
\hline II IV & 5 & 14 \\
\hline
\end{tabular}

Table 1: Patients characteristics. 
Citation: Onizuka M, Miyamura K, Miyamoto M, Ando K (2015) Noninfectious Pulmonary Complications after Stem Cell Transplantation and Induction of an Innate Immune Response. J Blood Disord Transfus 6: 277. doi:10.4172/2155-9864.1000277

Page 3 of 6

\section{Analysis of BPI polymorphisms}

Genomic DNA was purified from peripheral blood or BM obtained before transplantation. We investigated four BPI single nucleotide polymorphisms (SNPs) (rs5741798, rs1934917, rs5743530, rs2275954) using the TaqMan\ PCR method. The criteria for SNP selection were as follows: 1) minor allele frequency (MAF) $>0.25$ in the Japanese population; 2) SNP reported by previous study, or located with each different linkage disequilibrium blocks of the highest minor allele frequency. Because there are many differences in allele frequency between Caucasian and Japanese populations, we selected two SNPs that were not investigated in a previous report (rs1934917, rs5743530) [12] (Table 2). According to International HapMap Project data (http://hapmap.ncbi.nlm.nih.gov), we investigated the linkage disequilibrium among SNPs.

\begin{tabular}{|l|l|l|}
\hline & \multicolumn{2}{l|}{ minor allele frequency } \\
\hline rs No. & CEU & JPT \\
\hline rs5741798* & 0.175 & 0.411 \\
\hline rs1934917* & 0 & 0.322 \\
\hline rs5741800 & 0.439 & 0.143 \\
\hline rs5743507 & 0.134 & 0 \\
\hline rs3746476 & 0.098 & 0.202 \\
\hline rs4358188 & 0.491 & 0.167 \\
\hline rs5741806 & 0.382 & 0.439 \\
\hline rs5743530* & 0.009 & 0.476 \\
\hline rs2275954* & 0.455 & 0.464 \\
\hline rs1131847 & 0.348 & 0.5 \\
\hline CEU & & \\
\hline
\end{tabular}

$\mathrm{CEU}=$ Utah residents with Northern and Western European ancestry from the CEPH collection; JPT = Japanese in Tokyo, Japan.

"These SNPs were investigaed in this study.

Table 2: BPI rs SNP number and frequency.

\section{Definitions of NIPC and BOS}

NIPC was diagnosed according to established criteria, which included evidence of widespread alveolar injury from a multilobar infiltrate. Injuries such as these are readily apparent by chest $\mathrm{X}$-ray and by computed tomography (CT), and also be identified by the clinical symptoms of pneumonia, hypoxemia, and evidence of abnormal respiratory physiology, including restrictive impairment in a pulmonary function test. Bronchoalveolar lavage (BAL) and transbronchial lung biopsy were performed whenever possible.

Patients were diagnosed with BOS when they presented with significant dyspnea on exertion, decreased exercise tolerance, and a persistent nonproductive cough without any abnormality on chest CT and/or X-ray and comprehensive infectious disease. To exclude lower respiratory tract infections, we employed standard culture and staining methods for bacterial, viral, and protozoan pathogens. Serological tests were also performed to detect herpes simplex virus, varicella zoster, cytomegalovirus (CMV), and Epstein-Barr virus, and weekly CMV pp65 antigenemia testing has been performed on patients in Japan since 1995. The clinical features, laboratory test results, and imaging data were reviewed for all NIPC patients by an independent hematologist.

\section{Statistical analyses}

Allele frequencies among the study patients and controls were tabulated and compared by chi-square test and Fisher's exact test. For each hazard ratio, we calculated two-tailed $\mathrm{P}$ values and $95 \%$ confidence intervals.

\section{Results}

\section{BPI gene polymorphisms and pulmonary complications after HSCT}

NIPC occurred in 17 (14.0\%) of the patients in our cohort and we diagnosed $3(2.5 \%)$ patients with BOS. The SNPs typing was successfully completed for all patients and in all donors except for SNP rs5743530 in three donors. There is a significant difference in the distribution pattern of the rs5743530 CC, CT, and TT genotypes between NIPC patients and non-NIPC patients (Table 3). In patients with the rs1934917 and rs5743530 polymorphisms, the allele frequency was significantly different between patients with pulmonary complications and those with none (Allele T $85.0 \%$ vs. $66.8 \% ; \mathrm{P}=0.024$ and Allele C $72.5 \%$ vs. $51.5 \%$; $\mathrm{P}=0.015$, respectively) (Table 4 ). In donors with the rs5743530 polymorphism, the $\mathrm{C}$ allele was more frequent in the pulmonary complication group than in the group without complications $(72.5 \%$ vs. $49.0 \% ; \mathrm{P}=0.038$ ) (Table 4$)$. No significant relationships were noted between each of the other polymorphisms and the development of pulmonary complications.

\begin{tabular}{|c|c|c|c|c|c|c|}
\hline & \multicolumn{2}{|l|}{ NIPC } & \multicolumn{2}{|l|}{ without NIPC } & \multicolumn{2}{|l|}{$P$ value } \\
\hline & recipient n (\%) & donor $\mathbf{n}(\%)$ & recipient n (\%) & donor $\mathbf{n}(\%)$ & recipient $^{\dagger}$ & donor $^{\ddagger}$ \\
\hline \multicolumn{7}{|c|}{ rs5741798 } \\
\hline GG & $4(20.0)$ & $5(25.0)$ & $27(26.7)$ & $30(29.7)$ & & \\
\hline CG & $13(65.0)$ & $11(55.0)$ & $53(52.5)$ & $44(43.6)$ & & \\
\hline CC & $3(15.0)$ & $4(20.0)$ & $21(20.8)$ & $27(26.7)$ & 0.59 & 0.64 \\
\hline \multicolumn{7}{|c|}{ rs1934917 } \\
\hline TT & $14(70.0)$ & $12(60.0)$ & $44(43.6)$ & $47(46.5)$ & & \\
\hline
\end{tabular}


Citation: Onizuka M, Miyamura K, Miyamoto M, Ando K (2015) Noninfectious Pulmonary Complications after Stem Cell Transplantation and Induction of an Innate Immune Response. J Blood Disord Transfus 6: 277. doi:10.4172/2155-9864.1000277

Page 4 of 6

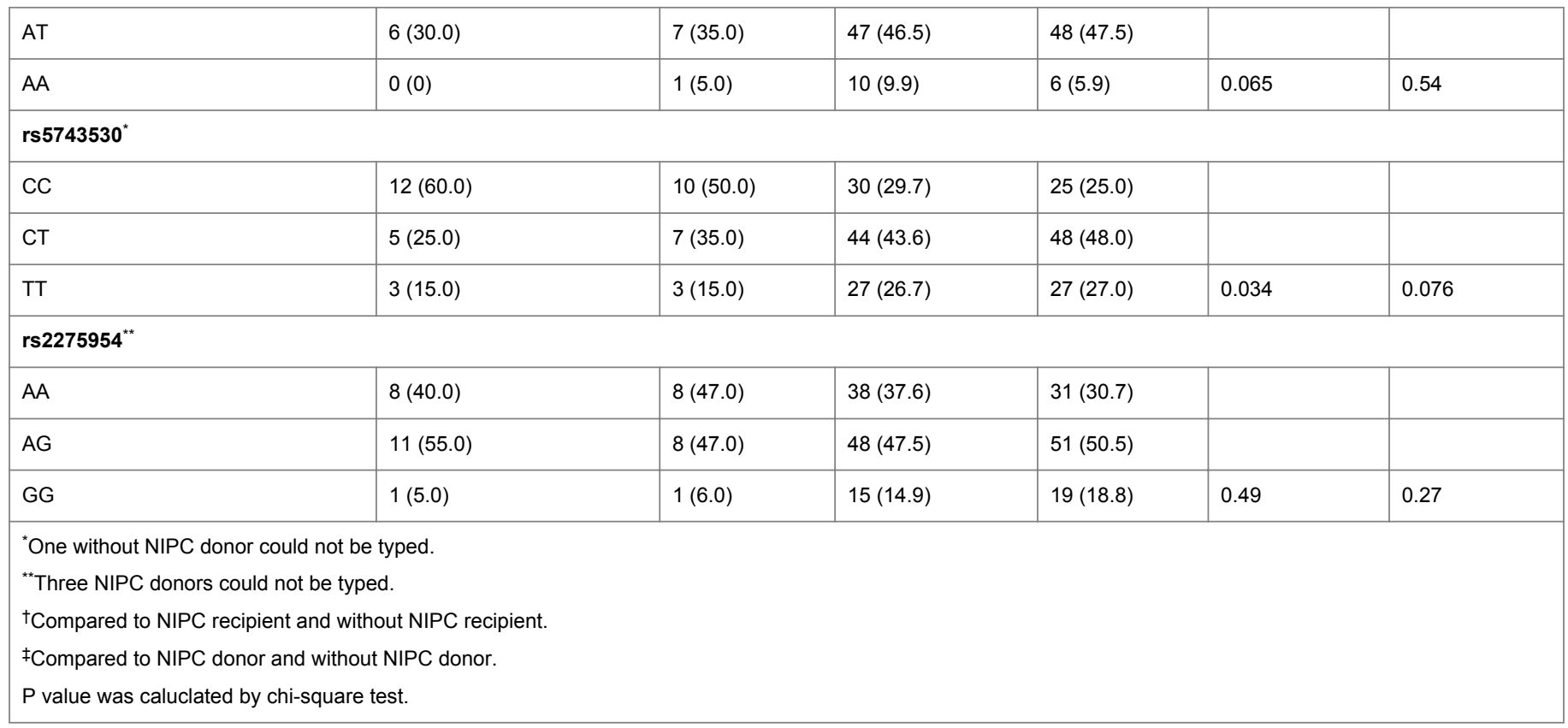

Table 3: Genotype Distribution of BPI polymorphism.

\begin{tabular}{|c|c|c|c|c|c|c|c|c|}
\hline & \multicolumn{2}{|l|}{ NIPC } & \multicolumn{2}{|l|}{ without NIPC } & \multicolumn{2}{|l|}{$P$ value } & \multicolumn{2}{|c|}{ Hazard Ratio $(\mathrm{Cl})$} \\
\hline & recipient n (\%) & donor $\mathbf{n}(\%)$ & recipient n (\%) & donor $\mathbf{n}(\%)$ & recipient $^{\dagger}$ & donor ${ }^{\ddagger}$ & recipient $^{\dagger}$ & donor $^{\ddagger}$ \\
\hline \multicolumn{9}{|c|}{ rs5741798 } \\
\hline G & $21(52.5)$ & $21(52.5)$ & $107(53.0)$ & $104(51.5)$ & & & & \\
\hline C & $19(47.5)$ & $19(47.5)$ & $95(47.0)$ & $98(48.5)$ & 1.00 & 1.00 & $\begin{array}{l}0.98 \\
(0.56-1.74)\end{array}$ & $1.04(0.59-1.82)$ \\
\hline \multicolumn{9}{|c|}{ rs1934917 } \\
\hline $\mathrm{T}$ & $34(85.0)$ & $31(77.5)$ & $135(66.8)$ & $142(70.3)$ & & & & \\
\hline A & $6(25.0)$ & $9(22.5)$ & $67(33.2)$ & $60(29.7)$ & 0.024 & 0.44 & $\begin{array}{l}2.45 \\
(1.07-5.58)\end{array}$ & $1.37(0.69-2.73)$ \\
\hline \multicolumn{9}{|c|}{ rs $5743530^{*}$} \\
\hline c & $29(72.5)$ & $27(72.5)$ & $104(51.5)$ & $98(49.0)$ & & & & \\
\hline T & $11(27.5)$ & $13(32.5)$ & $98(48.5)$ & $102(51.0)$ & 0.015 & 0.038 & $\begin{array}{l}2.16 \\
(1.13-4.12)\end{array}$ & $1.91(1.04-3.52)$ \\
\hline \multicolumn{9}{|c|}{ rs2275954 } \\
\hline A & $27(67.5)$ & $24(70.6)$ & $124(61.4)$ & $113(55.9)$ & & & & \\
\hline G & $13(32.5)$ & $10(29.4)$ & 78 (38.6) & $89(44.1)$ & 0.59 & 0.13 & $\begin{array}{l}1.25 \\
(0.68-2.30)\end{array}$ & $1.73(0.87-3.46)$ \\
\hline & $\begin{array}{l}\text { without NIPC donc } \\
\text { ee NIPC donors co } \\
\text { npared to NIPC rec } \\
\text { apared to NIPC dor } \\
\text { dicates confidence }\end{array}$ & $\begin{array}{l}\text { ald not be typec } \\
\text { t be typed. } \\
\text { and without NIF } \\
\text { d without NIPC } \\
\text { al. P value was }\end{array}$ & $\begin{array}{l}\text { cipient. } \\
\text { lated by Fisher's }\end{array}$ & & & & & \\
\hline
\end{tabular}

Table 4: Allele Distribution of BPI polymorphisms. 
Based on the HapMap project data, SNP rs574350 was in low linkage disequilibrium with three SNPs investigated in this study $(\mathrm{r} 2<0.6)$. However, these four SNPs did not construct the haplotype, thus we could not meaningfully analyze the relationship between haplotype and NIPC in this study.

Among all 121 patients and donors, the frequencies of the genotypes were highly similar to those predicted by the International HapMap project data and the Hardy-Weinberg equilibrium. The frequencies of alleles and genotypes for the four SNPs in all subjects were not significantly different from the International HapMap project data.

\section{Discussion}

The association of BPI gene polymorphisms with BOS after HSCT was first reported among a population that consisted of a mixture of ethnic groups [12]. Here we also confirmed an association between BPI gene polymorphisms and NIPC in a Japanese population. In general, there are remarkable variations in genetic polymorphisms among different ethnic groups $[18,19]$. Therefore, the association of a gene polymorphism with a disease in one ethnic group may not be true in other ethnic groups, and identifying a universal diseaseassociated gene in NIPC would require specifying a gene polymorphism association with disease that is independent of ethnicity. Here, we have at least demonstrated the importance of identifying the role of BPI in the development of HSCT-related pulmonary complications.

The BPI gene is located on chromosome 20 between q11.23 and q12 and it contains 16 exons. BPI selectively binds to LPS on the outer membrane of Gram-negative bacteria, causing immediate growth arrest followed by irreversible damage and then the death of the bacterium [20,21]. BPI also blocks the endotoxic effects of LPS and promotes phagocytosis of BPI-coated bacteria [21-23]. Previous reports also showed that very high plasma levels of BPI correlate with increased mortality $[24,25]$, and that plasma concentrations of BPI are significantly higher among community-acquired pneumonia patients than among healthy control subjects [26]. These findings and our present results suggest that the mechanism of developing NIPC is associated with pulmonary infection by Gram-negative pathogens. Thus, although the role of BPI in the development of NIPC after HSCT remains unknown, LPS is likely to be involved in the process. Experimental inhalation of a high dose of LPS stimulates the innate immune system, which results in an acute inflammatory response [27], whereas chronic exposure to significant levels of LPS induces chronic lung disease [15]. Animal models of lung injury after HSCT have also revealed that the inflammatory effector TNF- $\alpha$ is induced by both LPS and IPS [28]. Thus, it is possible that inflammatory events such as alloreaction, total body irradiation (TBI), and chemotherapy could enhance the levels of LPS and TNF- $\alpha$, and eventually lead to lung injury [29-31]. In fact, clinical risk factors for IPS include acute GVHD, conditioning with TBI, and conventional conditioning [28,32-34].

Genetic association studies provide a powerful tool to identify responding factors in diseases of unknown etiology. We have previously reported an angiotensin-converting enzyme gene polymorphism as a contributing factor in NIPC development after HSCT $[11,13]$. Inflammation in the lung induces NIPC especially in HSCT recipients who have a genetic propensity for fibrosis. This study has further revealed that the innate immune system is also associated with the development of pulmonary complications. Therefore, the extent of a recipient's pro-inflammatory response may dictate the level of pulmonary complications. Identification of the risks associated with these factors will facilitate better prediction, prevention, and care of pulmonary complications after HSCT.

\section{Acknowledgments}

We would like to thank Nanae Kunii and Miyoko Ikeguchi for their technical assistance. This study was partly supported by a Health and Labor Sciences Research Grant, Research on Human Genome, Tissue Engineering from the Ministry of Health, Labor and Welfare.

\section{References}

1. Clark JG, Madtes DK, Martin TR, Hackman RC, Farrand AL, et al. (1999) Idiopathic pneumonia after bone marrow transplantation: cytokine activation and lipopolysaccharide amplification in the bronchoalveolar compartment. Crit Care Med 27: 1800-1806.

2. Satoshi Y, Gregory Y, Kenneth RC, Shin M (2007) Bronchiolitis Obliterans Syndrome (BOS), Bronchiolitis Obliterans Organizing Pneumonia (BOOP), and Other Late-Onset Noninfectious Pulmonary Complications following Allogeneic Hematopoietic Stem Cell Transplantation. Biology of blood and marrow transplantation. Journal of the American Society for Blood and Marrow Transplantation 13: 749-759.

3. Tichelli A, Rovó A, Gratwohl A (2008) Late pulmonary, cardiovascular, and renal complications after hematopoietic stem cell transplantation and recommended screening practices. Hematology Am Soc Hematol Educ Program .

4. Soubani AO, Uberti JP (2007) Bronchiolitis obliterans following haematopoietic stem cell transplantation. Eur Respir J 29: 1007-1019.

5. Chien JW, Martin PJ, Gooley TA, Flowers ME, Heckbert SR, et al. (2003) Airflow obstruction after myeloablative allogeneic hematopoietic stem cell transplantation. Am J Respir Crit Care Med 168: 208-214.

6. Clark JG, Hansen JA, Hertz MI, Parkman R, Jensen L, et al. (1993) NHLBI workshop summary. Idiopathic pneumonia syndrome after bone marrow transplantation. Am Rev Respir Dis 147: 1601-1606.

7. Stella MD, Anne D, Jeffrey SM (2008) Human Polymorphism and Variable Outcomes of Cancer Chemotherapy and Transplantation. Biology of blood and marrow transplantation. Journal of the American Society for Blood and Marrow Transplantation 14:120-128.

8. Charles GM, Peter GB (2007) New Directions in the Genomics of Allogeneic Hematopoietic Stem Cell Transplantation. Biology of blood and marrow transplantation. Journal of the American Society for Blood and Marrow Transplantation 13:127-144.

9. Mullighan CG, Petersdorf EW (2006) Genomic Polymorphism and Allogeneic Hematopoietic Transplantation Outcome. Biology of Blood and Marrow Transplantation 12:19-27.

10. Dickinson AM, Middleton PG, Rocha V, Gluckman E, Holler E; Eurobank members (2004) Genetic polymorphisms predicting the outcome of bone marrow transplants. Br J Haematol 127: 479-490.

11. Onizuka M, Kasai M, Oba T, Atsuta Y, Terakura S, et al. (2005) Increased frequency of the angiotensin-converting enzyme gene $\mathrm{D}$-allele is associated with noninfectious pulmonary dysfunction following allogeneic stem cell transplant. Bone Marrow Transplant 36: 617-620.

12. Chien JW, Zhao LP, Hansen JA, Fan WH, Parimon T, et al. (2006) Genetic variation in bactericidal/permeability-increasing protein influences the risk of developing rapid airflow decline after hematopoietic cell transplantation. Blood 107: 2200-2207.

13. Miyamoto M, Onizuka M, Machida S, Toyosaki M, Amaki J, et al. (2014) ACE deletion polymorphism is associated with a high risk of noninfectious pulmonary complications after stem cell transplantation. International Journal of Hematology 99:175-183. 
Citation: Onizuka M, Miyamura K, Miyamoto M, Ando K (2015) Noninfectious Pulmonary Complications after Stem Cell Transplantation and Induction of an Innate Immune Response. J Blood Disord Transfus 6: 277. doi:10.4172/2155-9864.1000277

Page 6 of 6

14. Vernooy JHJ, Dentener MA, van Suylen RJ, Buurman WA, Wouters EFM (2001) Intratracheal Instillation of Lipopolysaccharide in Mice Induces Apoptosis in Bronchial Epithelial Cells. No Role for Tumor Necrosis Factor-\{alpha\} and Infiltrating Neutrophils. Am J Respir Cell Mol Biol 24: 569-576.

15. Vernooy JH, Dentener MA, van Suylen RJ, Buurman WA, Wouters EF (2002) Long-term intratracheal lipopolysaccharide exposure in mice results in chronic lung inflammation and persistent pathology. Am J Respir Cell Mol Biol 26: 152-159.

16. Cooke KR, Hill GR, Gerbitz A, Kobzik L, Martin TR, et al. (2000) Tumor necrosis factor-alpha neutralization reduces lung injury after experimental allogeneic bone marrow transplantation. Transplantation 70: 272-279.

17. Cooke KR, Hill GR, Crawford JM, Bungard D, Brinson YS, et al. (1998) Tumor Necrosis Factor-alpha Production to Lipopolysaccharide Stimulation by Donor Cells Predicts the Severity of Experimental Acute Graft-Versus-Host Disease. J Clin Invest 102:1882-1891.

18. Tishkoff SA, Kidd KK (2004) Implications of biogeography of human populations for 'race' and medicine. Nat Genet 36: S21-27.

19. Conrad DF, Jakobsson M, Coop G, Wen X, Wall JD, et al. (2006) A worldwide survey of haplotype variation and linkage disequilibrium in the human genome. Nat Genet 38: 1251-1260.

20. Levy O1 (1996) Antibiotic proteins of polymorphonuclear leukocytes. Eur J Haematol 56: 263-277.

21. Nupponen I, Turunen R, Nevalainen T, Peuravuori H, Pohjavuori M, et al. (2002) Extracellular release of bactericidal/permeability-increasing protein in newborn infants. Pediatr Res 51: 670-674.

22. Iovine NM, Elsbach P, Weiss J (1997) An opsonic function of the neutrophil bactericidal/permeability-increasing protein depends on both its N- and C-terminal?domains. PNAS 94:10973-10978.

23. Balakrishnan A, Marathe SA, Joglekar M, Chakravortty D (2013) Bactericidal/permeability increasing protein: a multifaceted protein with functions beyond LPS neutralization. Innate Immun 19: 339-347.

24. Calvano SE, Thompson WA, Marra MN, Coyle SM, de Riesthal HF, et al. (1994) Changes in polymorphonuclear leukocyte surface and plasma bactericidal/permeability-increasing protein and plasma lipopolysaccharide binding protein during endotoxemia or sepsis. Arch Surg 129: 220-226.

25. Rintala E, Peuravuori H, Pulkki K, Voipio-Pulkki LM, Nevalainen T (2000) Bactericidal/permeability-increasing protein (BPI) in sepsis correlates with the severity of sepsis and the outcome. Intensive Care Med 26: 1248-1251.

26. Jendeberg AL, Strålin K, Hultgren O (2013) Antimicrobial peptide plasma concentrations in patients with community-acquired pneumonia. Scandinavian Journal of Infectious Diseases 45: 432-437.

27. Jagielo PJ, Thorne PS, Watt JL, Frees KL, Quinn TJ, et al. (1996) Grain Dust and Endotoxin Inhalation Challenges Produce Similar Inflammatory Responses in Normal Subjects. Chest 110: 263-270.

28. Cooke KR, Yanik G (2004) Acute lung injury after allogeneic stem cell transplantation: is the lung a target of acute graft-versus-host disease? Bone Marrow Transplant 34: 753-765.

29. Cooke KR, Hill GR, Gerbitz A, Kobzik L, Martin TR, et al. (2000) Hyporesponsiveness of Donor Cells to Lipopolysaccharide Stimulation Reduces the Severity of Experimental Idiopathic Pneumonia Syndrome: Potential Role for a Gut-Lung Axis of Inflammation. J Immunol 165: 6612-6619.

30. Yao HW, Zhu JP, Zhao MH, Lu Y (2006) Losartan attenuates bleomycininduced pulmonary fibrosis in rats. Respiration 73: 236-242.

31. Bhalla KS, Folz RJ (2002) Idiopathic pneumonia syndrome after syngeneic bone marrow transplant in mice. Am J Respir Crit Care Med 166: 1579-1589.

32. Fukuda T, Hackman RC, Guthrie KA, Sandmaier BM, Boeckh M, et al. (2003) Risks and outcomes of idiopathic pneumonia syndrome after nonmyeloablative and conventional conditioning regimens for allogeneic hematopoietic stem cell transplantation. Blood 102: 2777-2785.

33. Crawford SW, Longton G, Storb R (1993) Acute graft-versus-host disease and the risks for idiopathic pneumonia after marrow transplantation for severe aplastic anemia. Bone Marrow Transplant 12: 225-231.

34. Down JD, Mauch P, Warhol M, Neben S, Ferrara JL (1992) The effect of donor $\mathrm{T}$ lymphocytes and total-body irradiation on hemopoietic engraftment and pulmonary toxicity following experimental allogeneic bone marrow transplantation. Transplantation 54: 802-808. 